\title{
Residencies in federal hospitals: incorporation of physical therapy in the system
}

\author{
Residências nos hospitais federais: inserção da fisioterapia no sistema
}

$F^{\prime}$

or decades, the development of multi-professional and healthcare residencies in Brazil have been based on the medical residency model, although questions this model have often arisen. It should be noted that there is a 30-year difference between the regulation and implementation of the National Commission of Medical Residency - CNRM (in 1977) and that of the National Commission of Multi-professional Residency in Healthcare - CNRMS (in 2007). Even though the CNRM itself is currently studying the medical residency curriculum guidelines and carefully reexamining their entire legal basis, the accumulated experience of this organization throughout its development process (with its successes and errors) cannot be disregarded.

One of the most important lessons learned from the evolution of medical residency in Brazil was the need for dialogue with managers of the Unified Health System (Sistema Único de Saúde - SUS) in order to meet local and regional demands for training specialists. As a consequence, progress has been made toward the development of multi-professional and professional area residencies. In the case of the multi-professional residency in healthcare, a national policy whose basic principle is integration with SUS guidelines has been clearly delineated ${ }^{1}$. The two main thrusts of the policy are to create a regulatory framework for such programs and to develop the funding parameters necessary for their implementation.

With respect to the regulatory framework in the context of the National System of Higher Education Assessment (SINAES), a directive has been issued by the Secretary of Higher Education of the Ministry of Education (MEC) regarding the conceptual consistency of higher education regulatory processes according to Decree 5,773/2006. Furthermore, the CNRMS has drawn up and implemented in its information system plans for regulating, assessing and supervising multi-professional and healthcare residency programs in accordance with the following guideline (http://portal.mec.gov.br/index.php?option=com_content\&view= article\&id=12263\&ativo=507\&Itemid=506). It should be pointed out that these programs are almost exclusively funded with public resources, and the Federal Government is the largest provider through the Ministries of Health and Education.

There is a clear trend towards valuing the multi-professional training model since it more effectively fulfills the requirements of professionals trained to work in teams and maintains the integrity of care. Of course, this does not necessarily exclude specifically-focused professional residencies, especially in certain areas important for SUS to function properly. There is also consensus about the need to support professional training in primary care, especially family health care, which is a high-priority strategy for the System. 
Moreover, there is also a need to invest in the development of professionals with above-average profiles for the hospital environment. It cannot be ignored that teaching hospitals continue to be an essential scenario for health-care training, in spite of the emphasis given in the National Curriculum Guidelines for healthcare courses to the early integration of students into primary care.

In this context, the Ministry of Education, as part of the National Program for Restructuring Federal University Hospitals (REHUF), established the Multi-professional Integrated Health Residency Program (PRIMS) in 2010, with 500 scholarships allocated to 35 programs throughout the country. In 2012, grants have been made available for the creation of 1,166 new vacancies. The PRIMS plan presupposes the need to integrate the academy and professional service, which means that professors from the involved universities must work jointly with instructors from the involved hospitals, not to mention coordination with state and municipal managers and social control by the Contract Monitoring Commission of each hospital. The definition of each program's core area should be based on the local demand for professionals and on the operational capacity of the involved institutions, with priority to state health policies set by the Ministry of Health, such as: Cardiovascular Care, Urgency and Emergency Care, Oncology, Intensive Care, Pediatrics, Gynecology, Geriatrics, Mental Health and Kidney Patient Care, etc. It has also been recommended that a mandatory rotation in the basic health network be implemented in units that have Family Health (SF) Teams, preferably those who also operate a Multi-professional Residency Program in Family Health in order to better exchange experiences.

PRIMS is an attempt to effectively change healthcare practice at these hospitals, with repercussions for the entire Brazilian hospital system, such as: integrated health team performance with an expanding concept of care; greater dialogue between the hospital and the primary health care network; the humanization of care; improvement in health quality indicators; reduced length of hospital stay; the expansion of home care programs; the implementation of new services in the hospital environment (e.g., mental health and oral health). In this scenario, Physical Therapy, as a field of professional practice fundamental to health care, should be increasingly integrated in these programs, which would include adapting models of professional training so that graduates are fully prepared for this new reality.

José Rubens Rebelatto

Director of the Department of Federal University Hospitals and Residencies in Health of the Secretariat of Higher Education of the Ministry of Education - MEC/SESu/DHR

Jeanne Liliane Marlene Michel

General Coordinator of Residencies in Health of the Directorate of Federal University Hospitals and Residencies in Health of the Secretariat of Higher Education of the Ministry of Education - MEC/SESu/DHR/CGRS

\section{References $\because \because$.}

1. Haddad AE, Ferreira ASF, Santos AA, Martins Netto CA, Andrade LR, Arruda MM, et al. Residência Multiprofissional em Saúde: experiências, avanços e desafios. Ministério da Saúde, 2006.

2. Law № 11.129 of 06 June 2005.

3. Decree $\mathrm{N}^{0} 5.773$ of 05 September 2006. 